\title{
Seismological evidence for the convergence of crustal stress orientation before large earthquakes*
}

\author{
Yongge Wan ${ }^{1,2, *}$ and Shuzhong Sheng ${ }^{1,2}$ \\ ${ }^{1}$ Institute of Disaster Prevention Science and Technology, Sanhe 065201, China \\ ${ }^{2}$ Institute of Geophysics, China Earthquake Administration, Beijing 100081, China
}

\begin{abstract}
Earthquakes are caused by the failure of faults, driven by tectonic stress build-up in the Earth's crust. To study the earthquake preparation process and assess regional earthquake potentials, it is vitally important to understand the crustal stress evolution process and identify its change in pattern associated with the seismogenic process. In this study we investigate the focal mechanism orientations of earthquakes in southern California from 1982 to 1999, basing on a focal mechanism catalog from Hauksson. We find that for the two large earthquakes occurred in southern California, the $1992 M_{\mathrm{W}} 7.3$ Landers and the $1999 M_{\mathrm{W}} 7.1$ Hector Mine, the orientations of focal mechanisms near the coming earthquake tend to converge to the stress direction promoting the rupture of the coming earthquake and align with its focal mechanism about half-year before its occurrence, suggesting that the tectonic stress field gets more organized in favor of the rupture of the event pre-seismically. The degree of stress convergence is measured by the orientation angle RMS (root mean square) between the preshocks' focal mechanisms and the focal mechanism of the large event studied, and its time series recorded the stress convergence process. The degree of anomalies, measured by the F-tests, indicates that the convergence of stress orientations become significant at $90 \%$ confidence about half-year prior to both the Landers and Hector Mine quakes, and it becomes even more prominent at $99 \%$ confidence right before the occurrences. Our study may be of significance for assessment of regional seismic potentials.
\end{abstract}

Key words: focal mechanism; stress orientation convergence; evolution; F-test

CLC number: P315.3 Document code: A

\section{Introduction}

For more than one hundred years, seismologist has been searching for earthquake prediction methods; however, there is no one reliable and practical at present (Geller, 1997). Many scientists were devoted to the attempts on various methods because earthquake prediction is of great importance in earthquake prevention and disaster reduction. For instance, Qian et al (1982) and Zhao et al (1996) have observed the geoelectric resistivity anomaly in quadrant spatial distribution before the Tangshan earthquake. But whether geoelectric measurement can be applied to earthquake prediction is not a deterministic conclusion (Geller, 1996). According to the study on relationship between $\mathrm{S}$ wave splitting and

\footnotetext{
* Received 7 September 2009; accepted in revised form 17 November 2009; published 10 December 2009.

• Corresponding author. e-mail: wanyg217217@vip.sina.com
}

stress variation, Crampin et al (1999) considered the S wave splitting in the view of relationship between stress variation, extensive dilatancy anisotropy and critical phenomenon related to earthquake prediction. It is reported that a successful "stress prediction" has been carried out in Iceland, although there is doubt on it (Seher and Main, 2004; Crampin et al, 2004). Basing on experiment observation of nonlinear instability before the rock rupture, the research group led by Yin Xiangchu proposed a load/unload response ratio (LURR) method and applied it to the practice in big earthquake prediction (Yin and Yin, 1991; Yin et al, 1995, 2000). Although this method is a relative good success, it also arose a discussion in seismological community (Smith and Sammis, 2004; Trotta and Tullis, 2006). These studies all have made a very good attempt. However, so far the problem of earthquake prediction is still a challenging research subject. 
As we know, the change of stress field caused by earthquake preparation is very little relative to the crustal tectonic stress, so the direction of crustal stress field is relatively stable. The ratio of stress field change to tectonic stress itself is an inconclusive scientific problem. If the accumulation and release of seismogenic crustal stress is very small and can be considered random fluctuation, the conclusion constitutes that earthquakes cannot be predicted (Geller et al, 1997). If the accumulation and release of seismogenic crustal stress cannot be taken as random fluctuation comparing with the crustal stress itself, earthquake can be predicted to some extent on the condition that the characteristic parameters of stress accumulation before an earthquake are obtained. The predecessors' studies mostly were concentrated on the absolute stress direction and value before earthquakes, where these parameters were treated as the characteristic parameters of stress accumulation before earthquake. However, comparing with the crustal stress itself, the accumulation and release of seismogenic crustal stress is very small, usually drowned out by observational noise, and therefore, its detection is very difficult. This may be the failure reason for many present earthquake prediction methods. Under the frame of elasticity, the precisely determination of stress value in seismogenic area is very difficult (Aki and Richards, 2002), but the stress direction can be obtained by using earthquake focal mechanism (Gephart and Forsyth, 1984; Michael, 1987; Gephart, 1990; Hardebeck and Michael, 2006). So if treating the convergence of stress field direction from focal mechanism of preshocks and that from mainshocks before a big earthquake as a parameter, maybe we can obtain some information about earthquake preparation process before a large earthquake.

In the late 1970s, Chen (1978) once proposed the method of treating the focal mechanisms consistency as a new parameter to describe the earthquake preparation process. However, the available foreshock focal mechanism data in his study were too few and he only used fault strike's standard deviation in each time interval to describe the earthquake preparation process without considering the dip and rake of the fault within the mechanism. Diao and Yu (1980) presented that the ratio of contrary signs to all the polarities of the $\mathrm{P}$ wave first motion of small earthquake in composite fault plane solution decreased before the 1976 Tangshan, Hebei, earthquake. They also found the similar phenomenon before the 1965 Yanqing, Beijing, earthquake. Diao et al (1994) analyzed the focal mechanism of small earth- quake before 1992 Kaoiki, Hawaii, earthquake, and found stress field variation before the mainshock. So they proposed the idea of earthquake prediction based on stress field variation in seismic source. Their group calculated the sum of the angles between the $P, T$ and $B$ axis of CMT catalogue in Kuril islands region and the pressure, dilatational and intermediate principal stress axis of tectonic stress in that region and treated the average value as the consistence parameter (Wang and Diao, 2005). They found the phenomena that the consistency parameter decreased before all the $M_{\mathrm{W}}>7.5$ earthquakes (Wang and Diao, 2005). However, the consistency parameter of focal mechanism they obtained shows obvious oscillation characteristics that make the discrimination of precursor information become difficult. This is because the adopted focal mechanism data is too limited, so the variation of consistency parameter of focal mechanism was observed in average-moving five points.

Kagan (1991) presented the method for calculating the three dimension spatial rotation angle to represent the focal mechanism orientation angle (FMOA for short in the following text) between two earthquakes' dislocation models by using quaternion method. Many studies gave the difference between focal mechanism orientations quantitatively with this method (e.g., Frohlich and Davis, 1999; Kagan and Jackson, 2000; Kagan, 2003; Bird and Kagan 2004; Okal, 2005; Pondrelli et al, 2006). Recently, Kagan (2007) proposed a simplified method of the spatial rotation between the double couple seismic source. This development provided a firm scientific foundation for the study on the consistency of focal mechanism before large earthquakes. In this study, the small earthquake focal mechanism catalog of southern California given by Hauksson (2000) is adopted and the FMOA algorithm (Kagan, 1991, 2007) for double couple source is used in studying the phenomena that small earthquakes focal mechanisms trend to that of mainshocks for two $M_{\mathrm{W}}>7.0$ earthquakes in southern California (the $1992 M_{\mathrm{W}} 7.3$ Landers earthquake and the $1999 M_{\mathrm{W}} 7.1$ Hector Mine earthquake). The results show that the above mentioned phenomenon is significant in both earthquakes. It has potential to be used in earthquake preparation process analysis.

\section{Data}

Hauksson (2000) presented the small earthquake focal mechanism catalog of southern California, covering the area of $114^{\circ} \mathrm{W}-122^{\circ} \mathrm{W}, 31.5^{\circ} \mathrm{N}-38^{\circ} \mathrm{N}$ from 1975 
to 2003 with total 66448 data of focal mechanism recorded including the focal mechanism whose magnitude is zero. These data provide the good opportunity to study that focal mechanisms of small earthquakes trend to those of the mainshocks in the two $M_{\mathrm{W}}>7.0$ earthquakes of Landers and Hector Mine. The focal mechanism solutions of this catalog are obtained by using $\mathrm{P}$ wave first-motion polarities, so it presents the initial rupture location and focal mechanism for big earthquake. In order to depict the general characteristics of big earthquakes, we use the catalog given by Kagan et al (2006) for the two big earthquakes' focal mechanism and centroid location, which were obtained on the basis of many researches on focal mechanism in southern California. The initial time of the Landers earthquake occurrence is 11:57, 28 June 1992, with its centroid location at $34.2^{\circ} \mathrm{N}, 116.437^{\circ} \mathrm{W}$ and strike, dip and rake angles $341^{\circ}, 70^{\circ}$ and $-172^{\circ}$ respectively. The initial time of the Hector Mine earthquake is 09:46, 16 October 1999 , with a centroid location at $34.594^{\circ} \mathrm{N}, 116.271^{\circ} \mathrm{W}$

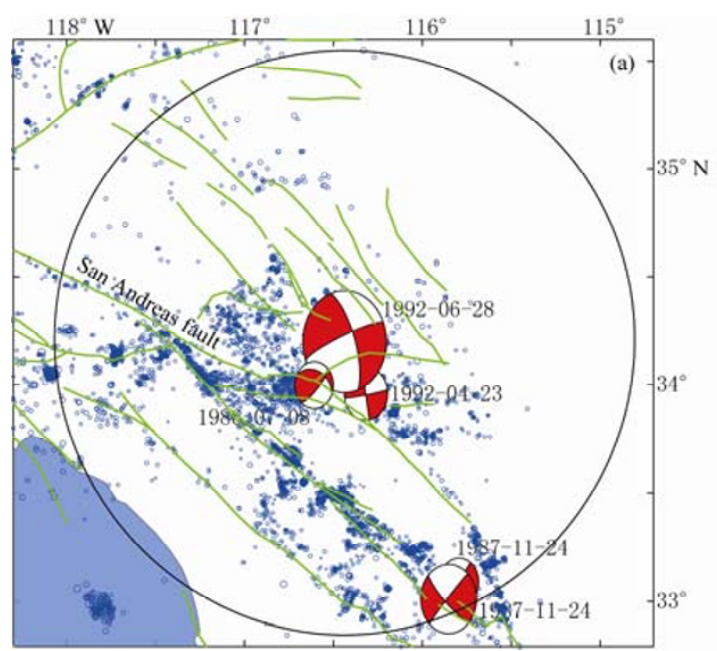

and strike, dip, slip of $336^{\circ}, 80^{\circ}$ and $174^{\circ}$ respectively.

In order to obtain the average range of variation in the FMOA of seismic focal mechanisms before the Landers and Hector Mine earthquakes to those of the mainshocks, we need a proper preshock phenomenon area, for if the selected area is too large, there will be more non-phenomenon factors affecting our result. However, if too small, lack of data available will make our result less reliable. Yu et al (2006) calculated the areas where the Coulomb stress change produced by the two earthquakes is over $0.01 \mathrm{MPa}$, which are equated with areas with radius of $150 \mathrm{~km}$ and $120 \mathrm{~km}$, and we adopted their result in our study. Taking the focal areas of the Landers and Hector Mine earthquakes as the centers and the $150 \mathrm{~km}$ and $120 \mathrm{~km}$ as the radius, we set the areas for our data collection to calculate the root mean square (RMS) of FMOA of small earthquakes to the mainshocks (Figure 1) and to study the phenomenon that stress direction trends to that encouraging the seismic rupture.

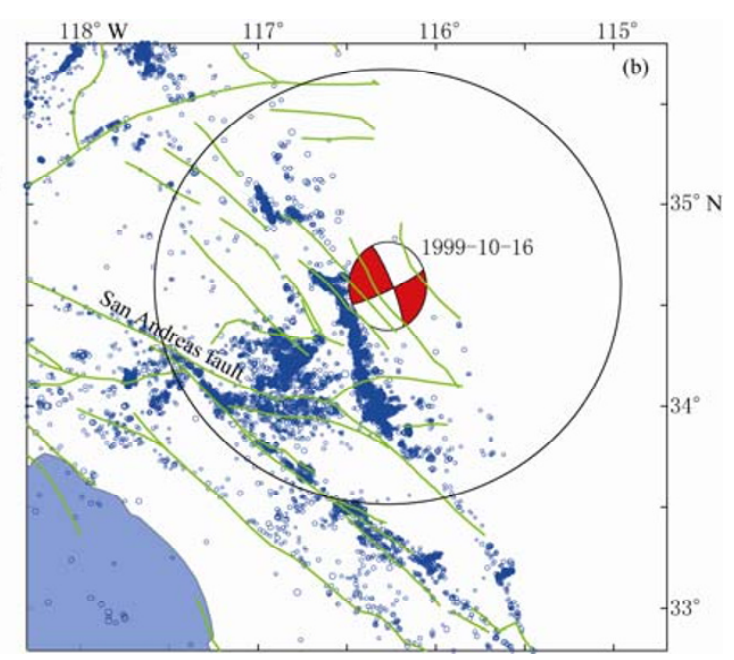

Figure 1 Epicentral distribution of focal mechanism data for the Landers (a) and Hector Mine earthquakes (b) used in this study. The locations of centroid moment tensors with $M_{\mathrm{W}}>6.0$ in the studied region and time period are presented by the lower-hemisphere projected beach balls with the red representing extensional quadrant. The green lines represent the fault of the studied area.

\section{Method}

The focal mechanism data 10 years before the Landers and Hector Mine earthquakes were used, and the average variance of the FMOA of all the earthquakes to the mainshocks was calculated by treating every half year as a time interval in the circle with a certain radius. The root mean square (RMS) of the FMOA of small earthquakes to the mainshocks was studied with average moving step of 0.1 year.
The FMOA of small earthquakes to the mainshock was calculated by using the algorithm presented by Kagan (1991, 2007). Kagan used a quaternion vector to represent an earthquake's focal mechanism, and one focal mechanism can be rotated into another by four rotation pattern around the pole, in which the minimum rotation angle represents the difference of focal mechanism orientation. The average FMOA was obtained by averaging every small earthquake's minimum rotation angle, which occurred at a certain time interval. As big- 
ger earthquakes can be observed by relatively more stations with smaller observational errors, we adopted the magnitude given by the catalog of Hauksson (2000) to weight the corresponding earthquake's FMOA and obtained the error of average FMOA as

$$
\sigma=\sqrt{\frac{\sum_{i=1}^{N} w_{i} \Phi_{i}^{2}}{\sum_{i=1}^{N} w_{i}}},
$$

where, $w_{i}$ is the weight of the earthquake in the time interval, and can be assumed as magnitude of the earthquake. $\Phi_{i}$ is the minimum rotation angle between the earthquake focal mechanism and the mainshock focal mechanism.

In order to set a criterion for objective evaluation of the probability of the earthquake, we adopted the F-test to determine the abnormality occurrence in the convergence of the focal mechanism of small earthquakes within a set period of time to that of the mainshock. The weight variance of the FMOA of all the earthquakes to the mainshocks within the defined period of time is

$$
\chi^{2}=N \sigma^{2},
$$

where $N$ is the number of earthquakes within the studied period, and its F-test can be expressed as

$$
F\left(\chi_{1}^{2}, \chi_{2}^{2}, N_{1}, N_{2}\right)=\frac{\chi_{1}^{2} / N_{1}}{\chi_{2}^{2} / N_{2}},
$$

where $N_{1}$ is the number of focal mechanisms within a period of 0.5 years, and $N_{2}$ the number of the total number of the focal mechanisms of all the earthquakes within the studied period. Here we can see that the F-test shows that the variance of the spatial rotation angle within a set period is different from that within a total period, i.e., the focal mechanisms within a set period trending to that of the mainshock show difference from those within the total period. The probability density function of the $F$ distribution is

$$
\begin{aligned}
& \varphi(x)= \\
& \left\{\begin{array}{ll}
\frac{\Gamma\left(\frac{N_{1}+N_{2}}{2}\right)}{\Gamma\left(\frac{N_{1}}{2}\right) \Gamma\left(\frac{N_{2}}{2}\right)} \cdot \frac{N_{1}}{N_{2}}\left(\frac{N_{1}}{N_{2}} x\right)^{\frac{N_{1}}{2}-1}\left(1+\frac{N_{1}}{N_{2}} x\right)^{-\frac{N_{1}+N_{2}}{2}} & x>0 \\
0 & x \leq 0
\end{array},\right.
\end{aligned}
$$

where $\varphi(x)$ is the probability density function.

$$
\Gamma(\alpha)=\left\{\begin{array}{ll}
\int_{0}^{\infty} x^{\alpha-1} \mathrm{e}^{-x} \mathrm{~d} x & \alpha>0 \\
\frac{\Gamma(\alpha+1)}{\alpha} & \alpha<0, \alpha \neq-1,-2, \cdots
\end{array},\right.
$$

$x$ is variable.

The probability is the integral of the $\varphi(x)$ within a defined range. The bigger statistic probability shows that the degree that the focal mechanism spatial direction within the studied period trends to the stress direction that encourages the mainshock rupture, is obviously different from that within the total period, therefore, and it can be treated as anomaly, hereinafter, called anomaly probability.

\section{Results}

Based on the method mentioned above, we calculated the root mean square of the difference of minimum spatial rotation angle of focal mechanism of small earthquakes before the Landers and Hector Mine earthquakes, the anomaly F-test probability and their corresponding relationships with the number of the focal mechanisms within the studied period and the Benioff strain (Figures 2 and 3). Data adopted for the Landers earthquake are those within 10 years before the occurrence of the event, while for the Hector Mine earthquake, we took data from one year after the Landers earthquake till six years before the Hector Mine earthquake. As for the latter we did not consider the data before and after the Landers earthquake so as to avoid the influence that the rupture process of Landers event might exert on the stress direction during the preparation process of the Hector Mine earthquake. Here we can see that before the Landers and Hector Mine earthquakes, both have a pre-seismic period of about 0.5 years when the phenomenon occurred that the root mean square of minimum spatial rotation angle dropped to its minimum value and the anomaly F-test probability rose to its maximum, which reflects the process that the statistic stress direction of the focal mechanism of the smaller earthquakes before the mainshock trends to that encouraging the rupture of the mainshock, and therefore, we can see that the process of earthquake preparation before the event is about 0.5 years.

Figure 2 is the root mean square of minimum spatial rotation angle of the stress direction corresponding to the rupture stress direction of the Landers earthquake within the area with a radius of $150 \mathrm{~km}$ before the Landers event, the anomaly F-test probability (Figure 2d) 
versus time, the number of focal mechanism and Benioff strain used at each interval. The number of seismic focal mechanisms reflects only the number of the data, excluding their magnitudes while the Benioff strain, on the contrary, reflects the overall strains released during the calculating interval. In addition, we produced as well the occurring times of the earthquakes before the Landers events such as the July 8, 1986 Desert Hot Springs $M_{\mathrm{W}} 6.1$ event, the two November 24, 1987 Superstition Hill ones that took place within roughly 12 hours with $M_{\mathrm{W}}$ as 6.1 and 6.6 respectively and the April 23, 1992 Joshua Tree $M_{\mathrm{W}} 6.2$ earthquake. These events all occurred within the coverage of $150 \mathrm{~km}$ from the seismic center of the Landers earthquake, but the root mean squares of the rotation angles and the chronological sequences of the anomaly F-test probability do not show obvious trace that other earthquakes are related to these $M_{\mathrm{W}}>6$ earthquakes during their occurrences. This may demonstrate: (1) that the stress field varying range of the $M_{\mathrm{W}}>6$ earthquakes is obviously smaller than the precursor anomaly range set by the $M_{\mathrm{W}}>7$ earthquakes, which makes the statistic data unidentifiable; or (2) that the focal mechanisms of these earthquakes are greatly different from that of the Landers earthquake.
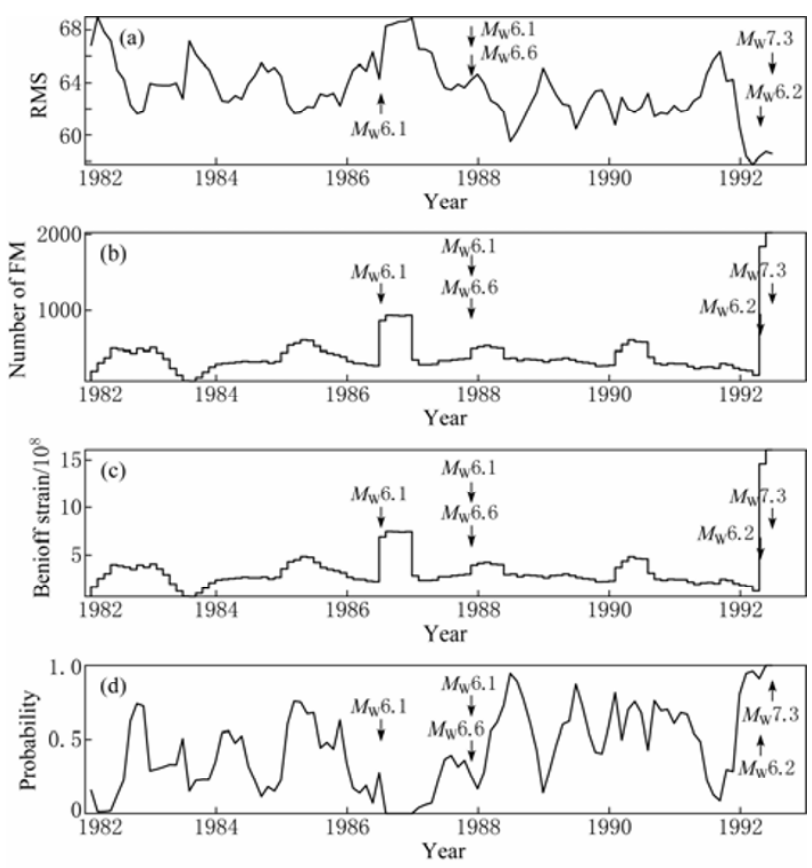

Figure 2 The root mean square of the difference of minimum spatial rotation angle of focal mechanism of small earthquakes in circle area with a radius of $150 \mathrm{~km}$ in Hauksson (2000) catalogue and that of the Landers earthquake (a), number of focal mechanisms (FM) used at each interval (b), Benioff strain at each interval (c) and anomaly F-test probability (d) versus time.
Figure 3 is the root mean square of minimum spatial rotation angle of the stress direction corresponding to the stress direction of the Hector Mine earthquake rupture within the area with a radius of $120 \mathrm{~km}$ before the Hector Mine event and the anomaly F-test probability (Figure $3 \mathrm{~d}$ ) versus time. During the period from the occurrence of the Landers earthquake to that of the Hector Mine event, no $M_{\mathrm{W}}>6.0$ earthquakes took place within the circle of $120 \mathrm{~km}$ from the seismic center, but $200 \mathrm{~km}$ to the west of this region, the Northridge $M_{\mathrm{W}} 6.7$ earthquake occurred in 1994. After the Northridge event seismic activities increased within the selected area (Figure $3 c$ and $d$ ), which might be the result of the triggering effect of the Northridge event. Though the Northridge earthquake may trigger the seismic activity in our studied area, the stress direction reflected by the focal mechanism in our calculation is not much deflected thereby. Only the root mean square of the difference of minimum spatial rotation angle of focal mechanism dropped to its lowest, and the corresponding anomaly F-test probability rose to its highest before the Hector Mine event, which remains the same until the occurrence of the event.
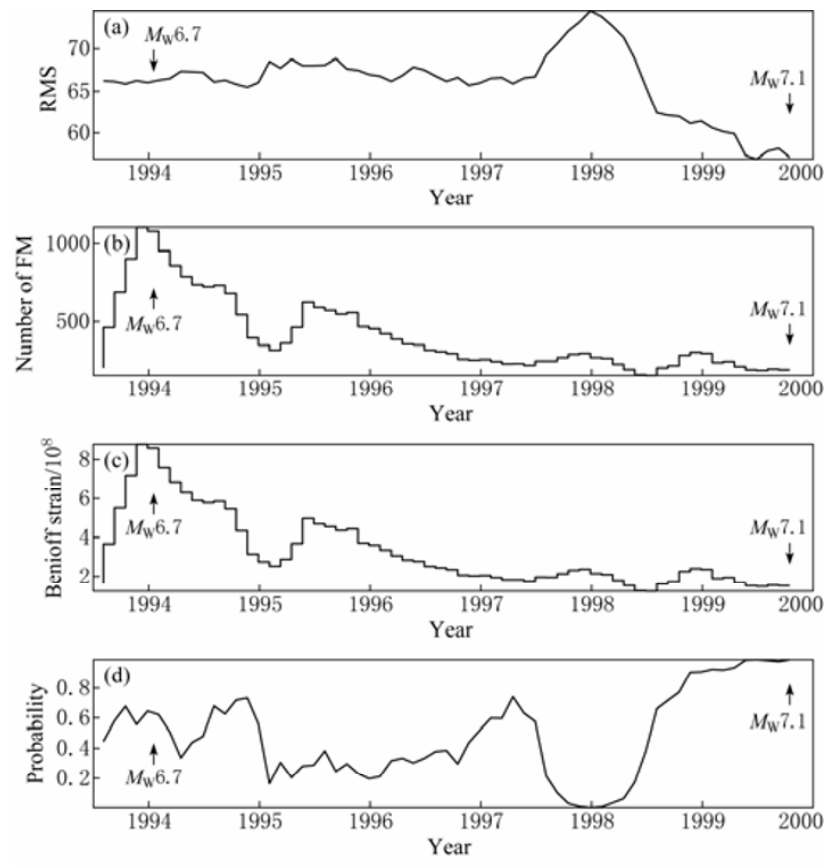

Figure 3 The root mean square of the difference of minimum spatial rotation angle of focal mechanism of small earthquakes in circle area with radius of $120 \mathrm{~km}$ in Hauksson (2000) catalogue and that of the Hector Mine earthquake (a), number of focal mechanisms used at each interval (b), Benioff strain at each interval (c) and anomaly F-test probability (d) versus time. 


\section{Discussion and conclusions}

By calculating the root mean square of the difference of minimum spatial rotation angle of focal mechanism of small earthquakes before the Landers and Hector Mine earthquakes and the anomaly F-test probability, we found that the two events both showed the phenomenon that the statistical stress direction of the focal mechanisms of the smaller earthquakes trends to that encouraging the mainshock rupture, which might be a precursor of earthquakes. The precursor emergence time is about 0.5 years before earthquakes. This study does not support the conclusion drawn by Geller et al (1997) that earthquakes are self-organized critical phenomena, therefore, unpredictable. At least, large events are predictable, as for smaller ones, however, we did not study yet due to the lack of data available. Our study may contribute to the seismic prediction study as a new start point for further development.

Among the root mean squares of the difference of spatial rotation angle before the two large earthquakes, there are also some lower extremes (Figure 2a and 3a) and some higher anomaly F-test probabilities (Figure $2 \mathrm{~d}$ and Figure 3d), where we found no corresponding earthquakes. This is not in line with the common sense mainly because: (1) the crustal stress may vary in different geologic structure units; (2) the spatial non-uniform distribution of the earthquake occurrences makes the crustal stress direction at the clusters of occurrences have bigger statistical weight and the areas where there are fewer occurrences have smaller; (3) earthquake occurrences also show chronological non-uniformity, which might lead to our neglecting the statistics of the spatial FMOA in certain areas where no earthquakes occurred at certain intervals but taking them into statistics at certain interval when earthquakes took place. How to take these complexities into consideration effectively so as to highlight the precursor information of spatial FMOA before earthquakes needs further study according to the individual occurring faults and their geophysical backgrounds. Despite of these uncertainties, we found that the anomaly probabilities obtained by F-test before the two events both kept increasing by $90 \%$ for half a year and exceeded $99 \%$ before their occurrences, which might be adopted as evidence and treated as the precursor of large earthquakes.

We only studied the phenomenon of foreshock's focal mechanism trending to that of the mainshock in the two $M_{\mathrm{W}}>7.0$ earthquakes in southern California, where better earthquake focal mechanism data are available. In the follow-up research in this aspect, we need to aim at earthquakes of smaller magnitudes. This research only provided the phenomena of foreshock's focal mechanism trending to that of the mainshock for the largest earthquake with the best available data.

In the study of accelerating moment release model, Bowman and King (2001) studied the possible region of earthquake precursor constrained by negative Coulomb stress change areas calculated by coseismic rupture model. And they found that several big earthquakes in California had precursors more consistent with the accelerating moment release model than that of circle area. The follow-up study on this research needs to consider this technology for selecting regions where earthquake precursors are obvious, so as to achieve possibly clearer information on foreshock's focal mechanism trending to that of the mainshock.

Acknowledgments We thank Dr. Zhengkang Shen and Prof. Zhonghuai $\mathrm{Xu}$ for their constructive comments and suggestions. This work was supported by the National Natural Science Foundation of China (40874022) and Public Utility Research Project (200808053).

\section{References}

Aki K and Richards P (2002). Quantitative Seismology. 2nd edition. University Science Books, Sausalito, California, 700 pp.

Bird P and Kagan Y Y (2004). Plate-tectonic analysis of shallow seismicity: apparent boundary width, beta, corner magnitude, coupled lithosphere thickness, and coupling in seven tectonic settings. Bull Seism Soc Amer 94(6): 2 380-2 399.

Bowman D D and King G C P (2001). Accelerating seismicity and stress accumulation before large earthquake. Geophys Res Lett 28(21): 4 039-4 042.

Chen Y (1978). Consistence of focal mechanism as a new parameter in describing seismic activity. Chinese J Geophys 19(2): 142-159 (in Chinese).

Crampin S, Volti T and Stefánsson R (1999). A successfully stress-forecast earthquake. Geophys J Int 138: F1-F5.

Crampin S, Volti T and Stefánsson R (2004). Response to "A statistical evaluation of a 'stress-forecast' earthquake" by T. Seher \&I. G. Main. Geophys $J$ Int 157: 194-199.

Diao G L and Yu X C (1980). Synthesis fault plane solution before and after Tangshan earthquake in Beijing-Tianjin-Tangshan-Zhangjiakou region. Northwestern Seismological Journal 2(3): 39-47 (in Chinese with English abstract).

Diao G L, Yu L M and Li Q Z (1994). Variation of stress field in the source region around a strong shock: an example. Acta Seismologica Sinica 7(1): 85-92.

Frohlich C and Davis S D (1999). How well constrained are well-constrained $T$, $B$, and $P$ axes in moment tensor catalogs? $J$ Geophys Res 104: 4 9014910.

Geller R J (1996). Debate on evaluation of the VAN method: Editor's introduction. Geophys Res Lett 23(11): 1 291-1 293.

Geller R J (1997). Earthquake prediction: A critical review. Geophys J Int 131: 425-450.

Geller R J, Jackson D D, Kagan Y Y and Mulargia F (1997). Earthquake cannot be predicted. Science 275: 1 616-1 617. 
Gephart J W (1990). FMSI: A FORTRAN program for inverting fault/slikenside and earthquake focal mechanism data to obtain the regional stress tensor. Computers and Geosciences 16: 953-989.

Gephart J W and Forsyth D W (1984). An improved method for determining the regional stress tensor using earthquake focal mechanism data: application to the San Fernando earthquake sequence. J Geophys Res 89: 9305 9320 .

Hardebeck J L and Michael A J (2006). Damped regional-scale stress inversions: Methodology and examples for southern California and the Coalinga aftershock sequence. J Geophys Res 111: B11310, doi:10.1029/ 2005JB004144.

Hauksson E (2000). Crustal structure and seismicity distribution adjacent to the Pacific and North America plate boundary in southern California. $J$ Geophys Res 105: 13 875-13 903.

Kagan Y Y (1991). 3-D rotation of double-couple earthquake sources. Geophys $J$ Int 106(3): 709-716.

Kagan Y Y (2003). Accuracy of modern global earthquake catalogs. Phys Earth Planet Inter 135(2-3): 173-209.

Kagan Y Y (2007). Simplified algorithms for calculating double-couple rotation. Geophys J Int 171(1): 411-418,doi:10.1111/j.1365-246X.2007.03538.x.

Kagan Y Y and Jackson D D (2000). Probabilistic forecasting of earthquakes. Geophys J Int 143(2): 438-453.

Kagan Y Y, Jackson D D and Rong Y F (2006). A new catalog of southern California earthquakes, 1800-2005. Seism Res Lett 77(1): 30-38.

Michael A J (1987). Use of focal mechanisms to determine stress: a control study. J Geophys Res 92 : 357-368.

Okal E A (2005). A re-evaluation of the great Aleutian and Chilean earthquakes of 1906 August 17. Geophys J Int 161(2): 268-282.

Pondrelli S, Salimbeni S, Ekstroem G, Morelli A, Gasperini P and Vannucci G (2006). The Italian CMT dataset from 1977 to the present. Phys Earth Planet Inter 159: 286-303.
Qian F Y, Zhao Y L, Yu M M, Wang Z X, Liu X W and Chang S M (1982). Abnormal variation of georesistivity before earthquakes. Sciencia Sinica (Series B) 9: 831-839 (in Chinese).

Seher T and Main I G (2004). A statistical evaluation of a 'stress-forecast' earthquake. Geophys J Int 157: 187-193.

Smith S W and Sammis C G (2004). Revisiting the tidal activation of seismicity with a damage mechanics and friction point of view. Pure Appl Geophys 161: 2 393-2 404.

Trotta J E and Tullis T E (2006). An independent assessment of the Load/Unload Response Ratio (LURR) proposed method of earthquake prediction. Pure Appl Geophys 163: 2 375-2 387.

Wang J G and Diao G L (2005). Consistent CMT solutions from Harvard University before great earthquakes in Kuril Islands and its significance for earthquake prediction. Acta Seismologica Sinica 18(2): 189-195.

Yin X, Chen X, Song Z and Yin C (1995). A new approach to earthquake prediction: The load/unload response ratio (LURR) theory. Pure Appl Geophys 145(3/4): 703-715.

Yin X, Wang Y, Peng K, Bai Y L, Wang H T and Yin X F ( 2000). Development of a new approach to earthquake prediction: Load/unload response ratio (LURR) theory. Pure Appl Geophys 157: 2 365-2 383.

Yin X C and Yin C (1991). The precursor of instability for nonlinear system and its application to earthquake prediction. Science in China (Series B) 34: $977-986$.

Yu H, Shen Z, Wan Y, Zhu Q and Yin X (2006). Increasing critical sensitivity of the Load/Unload Response Ratio before large earthquakes with identified stress accumulation pattern. Tectonophysics 428: 87-94, doi:10.1016/ j.tecto.2006.09.006.

Zhao Y L, Lu J, Li Z N, Qian F Y and Zhang H K (1996). Strain-geoelectric resistivity precursor and the virtual dislocation model to the Tangshan earthquake. Acta Seismologica Sinica 9(1): 103-108. 